\title{
Thermography Detects Subclinical Inflammation in Chronic Tophaceous Gout
}

MARTIN SCHIAVENATO, PhD, University of Miami School of Nursing and Health Studies; RALF G. THIELE, MD, Assistant Professor of Medicine, Department of Medicine, Allergy/Immunology and Rheumatology Division, University of Rochester, Rochester, New York, USA. Address correspondence to Dr. M. Schiavenato, University of Miami, School of Nursing and Health Studies, 5030 Brunson Drive, Coral Gables, FL 33146, USA.

E-mail: m.schiavenato@miami.edu. (J Rheumatol 2012;39:182-3; doi:10.3899/jrheum.110581)

Thermography, an imaging technique using radiation in the infrared range, has a long history in medicine, with reports in rheumatology dating back over 40 years ${ }^{1}$. It has also been long described as a measure of treatment response to nonsteroidal antiinflammatory drugs for gout ${ }^{2}$. Despite this, broad application of thermography has not been established because of a lack of precision and perceived limited value ${ }^{3}$. In a recent systematic review of the literature, thermography was not identified as an assessment tool in clinical trials of chronic gout ${ }^{4}$. However, recent advances in thermographic techniques sug-
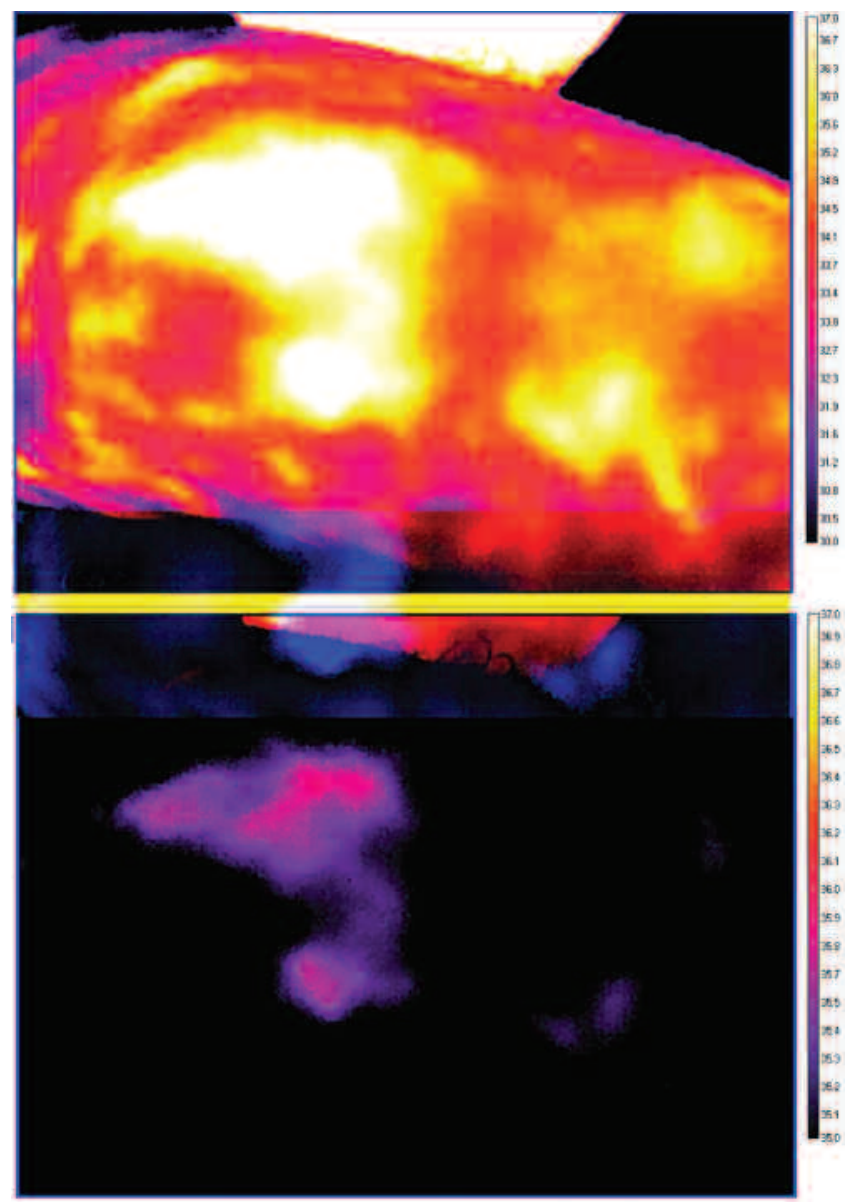

Figure 1. Affected right elbow: surface temperature $\geq 30^{\circ} \mathrm{C}$ (top) and $\geq 35^{\circ} \mathrm{C}$ (bottom). Maximum temperature measured was $36^{\circ} \mathrm{C}$. gest use in various medical applications including breast cancer detection, diabetes assessment, burn care, and others ${ }^{5}$.

We describe a case of subclinical hyperemia detected over gouty tophi in a 42-year-old man with a history of chronic tophaceous gout. Monosodium urate deposition in the first metatarsophalangeal (MTP) joints and the right, but not the left, olecranon bursa was seen on ultrasonography. Conventional radiography showed erosions with overhanging margins in MTP joints, but no abnormality in the elbow. On clinical examination, the involved elbow was not erythema-
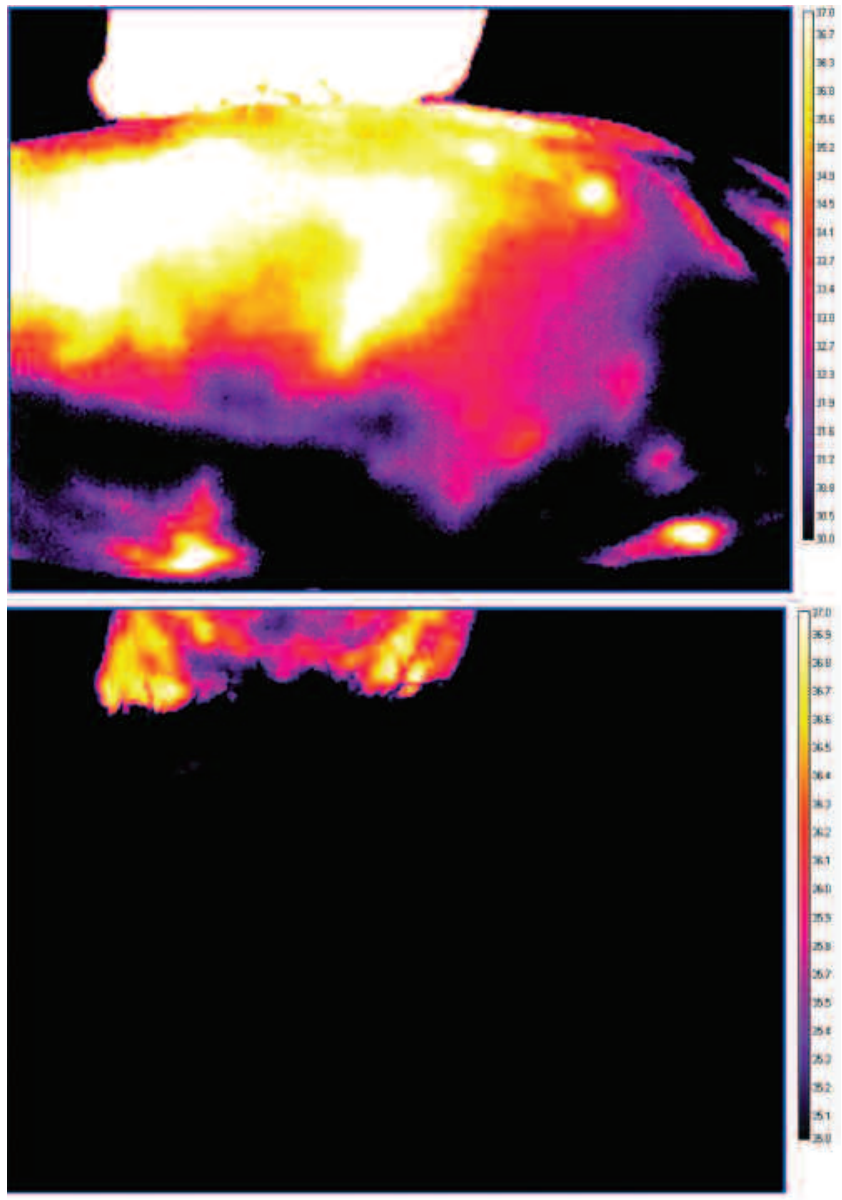

Figure 2. Unaffected left elbow: surface temperature $\geq 30^{\circ} \mathrm{C}$ (top) and $\geq 35^{\circ} \mathrm{C}$ (bottom). Maximum temperature measured $35.1^{\circ} \mathrm{C}$. 
tous or warm. Serum urate levels were elevated at $9.9 \mathrm{mg} / \mathrm{dl}$. Sedimentation rate and C-reactive protein had remained within normal limits. A thermal imaging camera (T400; Flir Systems Inc., Wilsonville, OR, USA) was used to compare elbows. The camera has $320 \times 240$ pixel resolution and thermal sensitivity of $0.05^{\circ} \mathrm{C}$ at $+30^{\circ} \mathrm{C}$. The maximum temperature was higher by about $1^{\circ} \mathrm{C}$ in the affected side (Figure 1) versus the unaffected side (Figure 2). Hyperemia and neovascularization were confirmed with power Doppler ultrasound on the affected side (Figure 3) but not on the unaffected side (Figure 4). A Toshiba Xario XG ultrasound unit with a PLT-1204BT transducer with a gray-scale frequency of 18 $\mathrm{MHz}$ and a Doppler frequency of 7.2 $\mathrm{MHz}$ was used.

Thermography correlated well with Doppler ultrasound and may be a safe, inexpensive imaging modality to document subclinical inflammation in patients with chronic tophaceous gout.

\section{REFERENCES}

1. Boas NF. Thermography in rheumatoid arthritis. Ann NY Acad Sci 1964;121:223-34

2. Ring EF, Collins AJ, Bacon PA, Cosh JA. Quantitation of thermography in arthritis using multi-isothermal analysis. II. Effect of nonsteroidal anti-inflammatory therapy on the thermographic index. Ann Rheum Dis 1974;33:353-6.

3. Assessment: Thermography in neurologic practice. The American Academy of Neurology, Therapeutics and Technology subcommittee. Neurology 1990;40(3 part 1):523-5.

4. Dalbeth N, Schauer C, MacDonald P, Perez-Ruiz F, Schumacher HR, Hamburger S, et al. Methods of tophus assessment in clinical trials of chronic gout: A systematic literature review and pictorial reference guide. Ann Rheum Dis 2011;70:597-604.

5. Head JF, Elliott RL. Infrared imaging: Making progress in fulfilling its medical promise. IEEE Eng Med Biol Mag 2002;21:80-5.

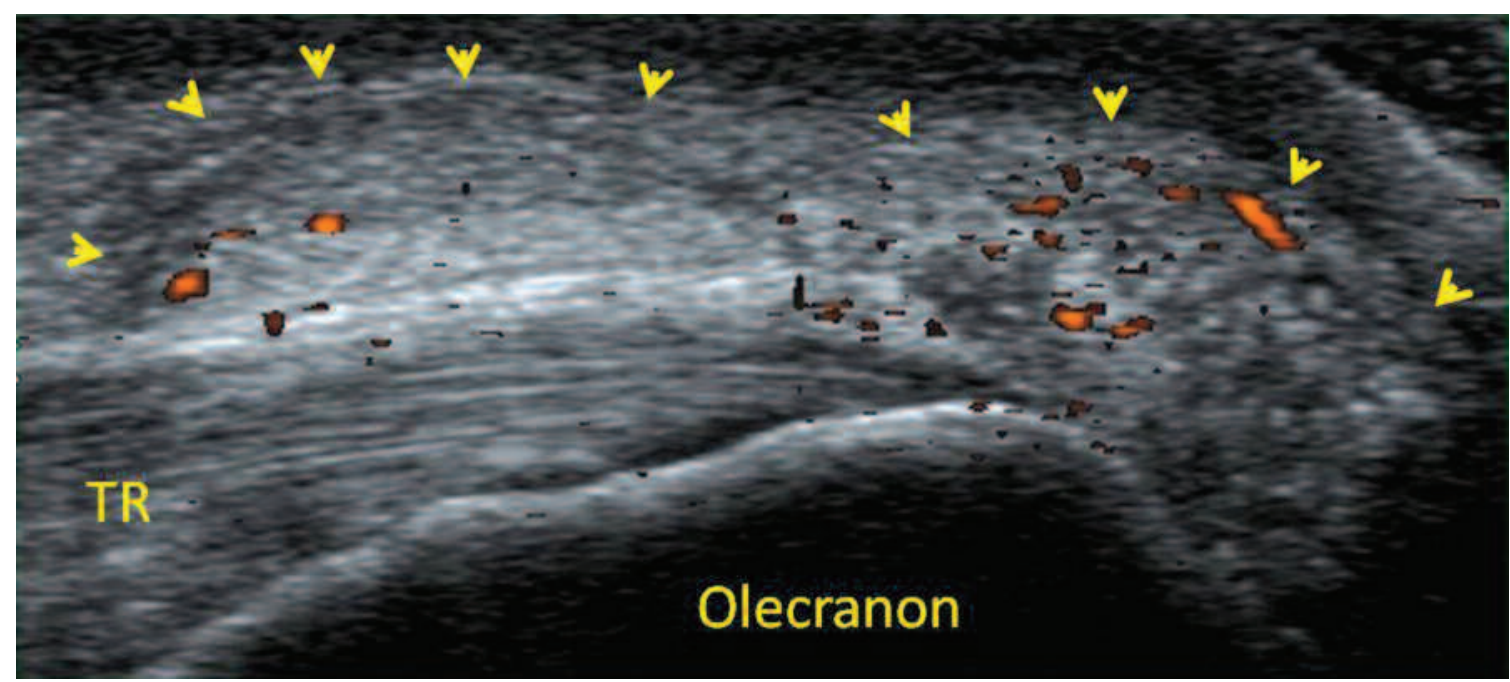

Figure 3. Affected right elbow: hyperechoic material representing monosodium urate tophus (arrowheads) is seen overlying insertion of triceps tendon (TR) into olecranon. Power Doppler signals indicated hyperemia.

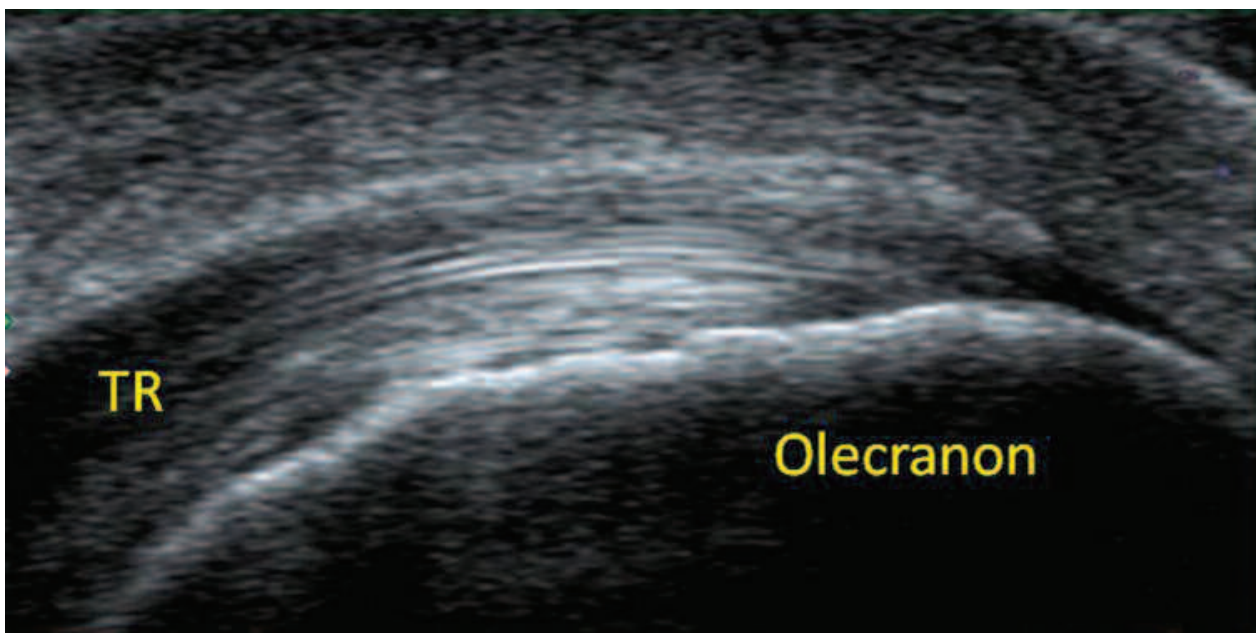

Figure 4. No Doppler signals seen over the unaffected, contralateral left elbow. Hyperechoic, tophaceous material is absent. 